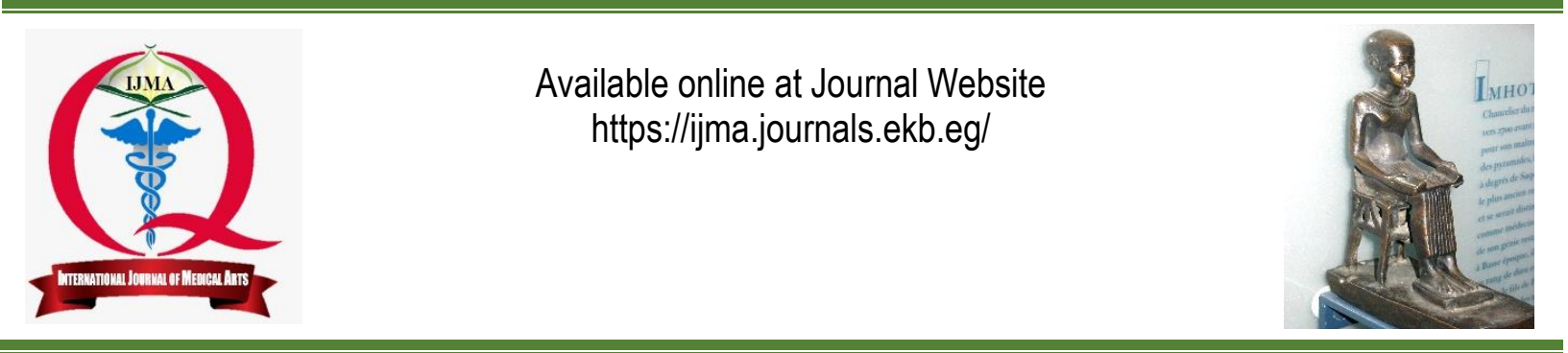

Original article

\title{
Clusterin and Psoriasis; What is The Relation?
}

\author{
Osama Hashemª ${ }^{\mathbf{a}}$ Zakaria Obaid ${ }^{\mathbf{a}}$; Hesham Abd Alsamee ${ }^{\mathbf{b}}$; Fatma Youssef ${ }^{\mathbf{c}}$
}

Department of Dermatology, Damietta Faculty of Medicine, Al-Azhar University, Egypt[a].

Department of Clinical Pathology, Damietta Faculty of Medicine, Al-Azhar University, Egypt[b].

Dermatology Department, Damietta General Hospital, Ministry of Health, Egypt $[c]$.

Corresponding author: Osama Hesham

Email: osama.os129@domazhermedicine.edu.eg

Received at: May 21, Revised at: September 17, 2019; Accepted at: September 29, 2019; Available online at: September 29, 2019

\section{ABSTRACT}

Background: Psoriasis is a chronic inflammatory immunologically mediated disease characterized by antigen presentation and keratinocytes hyperproliferation due to release of chemokines and cytokines from activated T-lymphocytes. Relationship between psoriasis and peripheral vascular diseases, increased risk of myocardial infarction and cerebrovascular diseases has been reported. Clusterin [apolipoprotein J] is a $75-80 \mathrm{KDa}$ disulfide-linked heterodimeric protein associated with apoptosis and clearance of cellular debris. Clusterin [CLU] is involved in many diseases related to oxidative stress, including neurodegenerative and inflammatory diseases.

Aim of the work: The aim of this study is to estimate the serum level of clusterin in patients with severe plaque psoriasis to evaluate its possible role in psoriasis pathogenesis and comorbidity.

Patients and methods: Sixty patients with severe plaque psoriasis having Psoriasis Area Severity Index [PASI] score more than 10 and Thirty healthy individuals as control were studied by enzyme linked immunosorbent assay for determination of serum clusterin levels.

Results: Serum levels of clusterin showed statistically significant increase in psoriatic patients than in controls.

Conclusion: Psoriatic patients show increase clusterin serum level compared with normal controls. This indicates that it may have a potential role in the pathogenesis of psoriasis and may be related to increase risk of cardiovascular diseases among psoriatic patients.

Keywords: Psoriasis; Clusterin; Psoriasis Area Severity Index; Keratinocyte; Apolipoprotein J.

This is an open access article under the Creative Commons license [CC BY] [https://creativecommons.org/licenses/by/2.0/]

Please cite this article as: Hashem 0, Obaid Z, Abd Alsamee H, Youssef F. Clusterin and Psoriasis; What is The Relation? IJMA 2020; 2[1]: 152-156. 


\section{INTRODUCTION}

Psoriasis is a chronic disease of inflammatory nature, marked by aberrant epidermal keratinocytes differentiation with hyperproliferation, with infiltration by T-lymphocyte and changes in vascular endothelium of dermal layer [e.g., angiogenesis, dilatation and development of high endothelial venules[ ${ }^{[1]}$. Psoriasis is associated with serious comorbidities ${ }^{[2]}$.

It is considered as an independent risk factor for myocardial infarctions and coronary artery calcification [3].

Subjects with psoriasis had higher rates of dyslipidemia, insulin resistance, hypertension and obesity which is a risk factors for adverse cardiovascular problems [2].

Clusterin [apolipoprotein J] is a heterodimeric, disulfide-linked protein, $75-80 \mathrm{kDa}$ molecular weight, which is associated with apoptosis and removal of cellular debris. Clusterin is encoded by the CLU gene on chromosome 8 in humans. CLU is a molecular chaperone aiding protein folding of secreted proteins. It plays a role in different pathological conditions linked to oxidative stress, including inflammatory disorders, neurodegenerative diseases, and malignant conditions ${ }^{[4]}$.

Clusterin is a protein element of high-density lipoproteins [HDLs]. It had a protective action in different diseases like myocarditis and atherosclerosis. Clusterin associated HDLs are inversely correlated with incidence of coronary heart disease and, thus, could be considered as an inhibitor of future coronary events [5].But recently Zhu et el. concluded that clusterin increased in patients with early coronary artery diseases in a Chinese populations ${ }^{[6]}$.

Over expression of the secretory CLU protects the cell from apoptosis which induced by cellular stress, such as radiotherapy and chemotherapy ${ }^{[7]}$.

\section{AIM OF THE WORK}

The present work designed to estimate CLU in psoriatic patients with severe plaque psoriasis and its possible role in pathogenesis and comorbidity.

\section{PATIENTS AND METHODS}

The current study comprised a total of 60 patients with severe plaque psoriasis, diagnosed according to the typical appearance of the skin lesions. In addition to 30 healthy subjects served as controls. All persons were recruited from the outpatient clinic of Dermatology and Venereology Department Damietta Faculty of Medicine, Al-Azhar University. All the studied patients have severe plaque psoriasis [psoriasis area severity index [PASI] >10], and age over 18 years. On the other hand, patients with psoriasis and having another systemic disease known to affect Clusterin serum level like Diabetes Mellitus and Metabolic Syndrome, and those receiving any medications known to affect Clusterin serum level, were excluded from the study.

All persons were subjected to full History taking [personal, present illness, family history, other dermatological or systemic diseases, and previous therapy]. A written consent was signed by each participant before initiation of the study.

In addition, all underwent careful general examination including joint examination, nails, and clinical manifestations indicative of systemic diseases. Furthermore, skin lesions in all patients were examined clinically and involved body surface area; scaling, erythema, thickness of lesions were recorded.

Every patient was subjected to PASI score calculations which estimates the disease severity in relation to three parameters including: redness [R], thickness [infiltration] [T] and scaliness [desquamation] [S] ${ }^{[8]}$.

Five millimeters of venous blood were collected from each patient and control. The blood samples were left to clot then subjected to centrifugation for 15 minutes at 1000 round per minute to separate serum. The serum samples were removed using sterile pipette and ach sample was coded with a number and stored at $-20^{\circ} \mathrm{C}$ until used.

Serum clusterin determined by a commercially available ELISA kit, manufactured at Chinese Immunodiagnostic Company called Sun Reds; kit's number is 201-12-1190. The kit working by a double antibody sandwich technique. The samples added to an enzyme of monoclonal antibody precoated with human clusterin, incubated, then clusterin antibodies labeled with biotin and combined with streptavidin-HRP added to constitute immune 
complex, then carried out to incubation and washed again to eliminate the uncombined enzyme, then chromogen solution A and B were added. The average values for absorbance were calculated for each set of controls, non-specific binding controls, and samples. A standard curve was built by plotting mean values from each standard against its concentration on the vertical [y] axis and concentration on the horizontal $[x]$ one. For each sample, mean absorbance was used to estimate the corresponding concentration from the standard curve. The results have been calculated automatically using a 4-parameter logistic curve fit.

Statistics: Statistical presentation and analysis were calculated using the mean and standard deviation for numerical data, frequency and percent distribution for categorical data. Groups compared by student [t] and chi-square tests. Also, to assess the strength of association between two quantitative variables, Pearson correlation coefficient $[r]$ was calculated. All analyses were done by statistical package for social science [SPSS Inc., USA]. $P$ is significant if $<0.05$ at confidence interval $95 \%$.

\section{RESULTS}

The present study was conducted on 60 psoriasis patients. Their mean age was 44.5 years, they were 43 males [71.7\%] and 17 females [28.3\%]. In addition, 30 healthy subjects [matched for age and gender] were included as controls. Psoriatic patients significantly showed higher association with family history of psoriasis. Mean PASI score was 18.6, mean duration was 13.9 years; Most of cases had gradual onset [91.7\%] and progressive course [98.3\%]. Nail was affected in $63.3 \%$ of all studied cases. All of them had plaque psoriasis [Table 1].

All of studied cases received topical treatment, $41.7 \%$ received systemic treatment and $71.7 \%$ received phototherapy. Psoriasis cases have significantly higher serum clusterin level when compared to control group [Table 2].

No significant differences were found in serum clusterin level according to gender, disease onset and treatment in all studied cases [Table 3].

Clusterin levels showed significant positive correlation with PASI score. Otherwise, no significant correlation was found in clusterin level with other studied parameters in all psoriasis cases [Table 4].

Table [1]: Clinical data of all studied cases

\begin{tabular}{|c|c|c|c|c|}
\hline \multirow{2}{*}{ PASI score } & & \multirow[b]{2}{*}{ mean $\pm S D$} & \multicolumn{2}{|c|}{$\begin{array}{l}\text { Psoriasis } \\
\mathrm{N}=60\end{array}$} \\
\hline & & & 18.6 & 4.2 \\
\hline \multicolumn{2}{|l|}{ Duration [years] } & mean $\pm S D$ & 13.9 & 4.1 \\
\hline \multirow{2}{*}{ Age of onset [years] } & Gradual & $\mathrm{N}, \%$ & 55 & 91.7 \\
\hline & Sudden & $\mathrm{N}, \%$ & 5 & 8.3 \\
\hline \multirow{2}{*}{ Course } & Stationary & $\mathrm{N}, \%$ & 1 & 1.7 \\
\hline & Progressive & $\mathrm{N}, \%$ & 59 & 98.3 \\
\hline Site & Nail & $\mathrm{N}, \%$ & 38 & 63.3 \\
\hline Clinical type & Plaque Psoriasis & $\mathrm{N}, \%$ & 60 & 100.0 \\
\hline
\end{tabular}

Table [2]: Comparison of Clusterin concentration between the two studied groups.

\begin{tabular}{|c|c|c|c|c|c|c|c|}
\hline & & \multicolumn{2}{|c|}{$\begin{array}{l}\text { Control } \\
N=20\end{array}$} & \multicolumn{2}{|c|}{$\begin{array}{c}\text { Psoriasis } \\
\mathrm{N}=60\end{array}$} & Test & P \\
\hline Clusterin & mean $\pm S D$ & 14.6 & 4.2 & 105.3 & 28.3 & $t=10.2$ & $<0.001$ \\
\hline
\end{tabular}


Table [3]: Comparison of serum Clusterin level according to gender, disease onset and treatment in all studied cases.

\begin{tabular}{|c|c|c|c|c|c|}
\hline & \multicolumn{2}{|c|}{$\begin{array}{c}\text { Serum Clusterin } \\
\text { concentration }\end{array}$} & \multirow[t]{2}{*}{ Test } & \multirow[t]{2}{*}{$\mathbf{P}$} \\
\hline & & Mean & SD & & \\
\hline \multirow[t]{2}{*}{ Gender } & Male [n=43] & 100.8 & 30.9 & \multirow[t]{2}{*}{1.1} & \multirow[t]{2}{*}{.255} \\
\hline & Female [n=17] & 116.6 & 33.3 & & \\
\hline \multirow[t]{2}{*}{ Onset } & Gradual [n=55] & 107.3 & 32.4 & \multirow[t]{2}{*}{1.1} & \multirow[t]{2}{*}{.277} \\
\hline & Sudden [n=5] & 82.6 & 25.8 & & \\
\hline \multirow[t]{4}{*}{ Treatment } & No systemic [n=35] & 98.5 & 32.3 & \multirow[t]{2}{*}{1.3} & \multirow[t]{2}{*}{.205} \\
\hline & Systemic [n=25] & 114.6 & 52.5 & & \\
\hline & No phototherapy [n=17] & 92.9 & 30.9 & \multirow[t]{2}{*}{1.2} & \multirow[t]{2}{*}{.217} \\
\hline & Phototherapy [n=43] & 110.1 & 31.4 & & \\
\hline
\end{tabular}

$\mathrm{N}$, number; SD, standard deviation; numerical data are compared using $\mathrm{t}$ test.

Table [4]: Correlation of Clusterin level with other studied parameters in all psoriasis cases.

\begin{tabular}{|l|c|c|}
\hline \multirow{2}{*}{} & \multicolumn{2}{|c|}{ Clusterin } \\
\cline { 2 - 3 } & $\mathrm{N}=60$ \\
\hline Age [years] & -.071 & $\mathrm{P}$ \\
\hline Gender & .149 & .590 \\
\hline History of other skin disease & .046 & .726 \\
\hline History of systemic disease & -.016 & .904 \\
\hline Family history & .061 & .645 \\
\hline PASI score & .624 & $<0.001$ \\
\hline Duration [years] & -.040 & .764 \\
\hline
\end{tabular}

[r]: correlation coefficient; Pearson correlation was used.

\section{DISCUSSION}

The results of present study show psoriasis cases have significantly higher clusterin level when compared to control group. So, it may be involved in pathogenesis of psoriasis.

These results matched with study done by Buquicchio et al. ${ }^{[9]}$ who demonstrated the presence of significantly high concentrations of clusterin in serum of psoriatic patients and they concluded that clusterin might be a useful biomarker for psoriasis.

The mechanisms responsible for such a clusterin upregulation are unknown. Kuryłowicz et al.[10] suggested that owing to the inflammatory nature of psoriasis, upregulation of the antiinflammatory and antioxidant clusterin might be a compensatory and defense mechanism.

Moreover, in another study, the presence of psoriasis- metabolic syndrome pathogenic interactions have been confirmed [11].

In psoriatic patients it is well known that increased susceptibility to adverse cardiovascular events, is mediated by proinflammatory cytokines, like tumor necrosis factor- alpha [TNF-a], interleukin [IL-1], and cardiotropin-1[12]. However recently Zhu et al.[6] concluded that serum values of clusterin were increased in premature form of coronary artery disease [CAD], and clusterin could represent a possible diagnostic indicator for premature CAD.

In the light of these data, the results of elevated clusterin in psoriasis appear to be interesting. However, these data could not explain the etiology of the clusterin elevation, which could be attributed to inflammatory nature of psoriasis, destruction of endothelial cells, or other risk factors for CAD.

On the other hand, the study of Garcia- 
Rodriguez et al.[13]observed that plasma clusterin was reduced in psoriasis compared with healthy controls but the study had a small sample size.

It has been postulated that clusterin, may exert a protective role against atherosclerosis through its role in transportation of circulating cholesterol to the liver [13].

From the present study, we can conclude that psoriatic patients show increase clusterin levels and it may play a potential role in the pathogenesis of the disease and may be related to increase risk of cardiovascular diseases risk among psoriatic patients. In addition, clusterin level showed significant positive correlation with PASI score. This suggests that it could be a useful biomarker for disease severity.

\section{REFERENCES}

1-Coimbra S, Figueiredo A, Castro E, Rocha-Pereira P, Santos-Silva A. The roles of cells and cytokines in the pathogenesis of psoriasis. Inter J Derma. 2012; 51: 389-398. [DOI:10.1111/j.1365-4632.2011.05154.x].

2-Gottlieb A, Korman NJ, Gordon KB, Feldman SR, Lebwohl M, Koo JY, et al. Guidelines of care for the management of psoriasis and psoriatic arthritis, Section 2. Psoriatic arthritis: Overview and guidelines of care for treatment with an emphasis on the biologics. J Am Acad Dermatol.2008; 58:851-64. [DOl:10.1016/j.jaad. 2008. 02.040].

3-Gelfand JM, Neimann AL, Shin DB, Wang X, Margolis DJ, Troxel AB. Risk of myocardial infarction in patients with psoriasis. JAMA 2006; 296:1735-41. [DOI:10.1001/jama.296.14.1735].

4-Sansanwal P, Li L, Sarwal MM. Inhibition of intracellular clusterin attenuates cell death in nephropathic cystinosis. J Am Soc Nephrol. 2015; 26 [3]: 612-25. [DOI: 10.1681/ASN.2013060577].
5-Negre-Salvayre A, Dousset N, Ferretti G, Bacchetti T, Curatola G, Salvayre R. Antioxidant and cytoprotective properties of high-density lipoproteins in vascular cells. Free Radic Biol Med. 2006; 41: 1031-40. [DOI:10.1016/j.freeradbiomed.2006.07.006].

6- Zhu HI, Liu MI, Pan HI, Wang LI, Yang HI, Yan K, et al. High serum clusterin levels are associated with premature coronary artery diseases in a Chinese population. Diabetes Metab Res Rev. 2019: 1305-18. [DOI: 10.1002/dmrr.3128].

7-Koltai T. Clusterin: a key player in cancer chemoresistance and its inhibition. OncoTargets Ther. 2014; 7: 447-56. [DOI:10.2147/OTT.S58622].

8- Langley RG, Ellis CN. Evaluating psoriasis with psoriasis Are and severity index, psoriasis Global Assessment and Lattice System Physicians Global Assessment. J Am Acad Dermtol. 2004; 51:563-9. [DOl: 10.1016/ j.jaad.2004.04.012].

9-Buquicchio R, Foti C, Loconsole F, Polimeno L, Ventura MT. Clusterin serum level: How does it affect psoriatic patients? J Biol Regul Homeost Agents 2017; 31[3]: 785-89. [PMID:28958138].

10- Kuryłowicz A, Nauman J. The role of nuclear factor kappa $B$ in the development of autoimmune diseases: a link between genes and environment. Acta Biochim Pol 2008; 55:629-47.[PMID:19081854].

11- Dey AK, Joshi AA, Chaturvedi A, Lerman JB, Aberra TM, Rodante JA, et al. Association between skin and aortic vascular inflammation in patients with psoriasis: a case-cohort study using positron emission tomography/computed tomography. JAMA Cardiol. 2017; 2[9]: 1013- 1018. [DOI: 10.1001/ jamacardio. 2017.1213].

12- Aronis KN, Kim YB, Mantzoros CS. Clusterin [apolipoprotein J]: wither link with diabetes and cardiometabolic risk. Metabolism 2011; 60:747-8. [DOI:10.1016/j.metabol.2010.12.013].

13- Garcia-Rodriguez S, Arias-antiago S, Perandres-Lopez R, Orgaz-Molina J, Castellote L, Buendía-Eisman A, et al. Decreased plasma levels of clusterin in patients with psoriasis. Actas Dermosifiliogr. 2013; 104[6]: 497503. [DOI: 10.1016/j.ad.2012.11.019]. 